\title{
An efficient recyclable magnetic material for the selective removal of organic pollutants
}

\author{
Clément Monteil ${ }^{1}$, Nathalie Bar ${ }^{1}$, Agnès Bee ${ }^{2}$ and Didier Villemin ${ }^{* 1}$
}

\author{
Full Research Paper \\ Address: \\ 1UMR CNRS 6507 LCMT, Normandie Université -ENSICAEN, 6 \\ boulevard du Maréchal Juin, 14050 Caen, France; Tel: +3323145 \\ 2840 and 2 UMR CNRS 8234 PHENIX, Université Pierre et Marie \\ Curie, 75252 Paris Cedex 05, France \\ Email: \\ Didier Villemin* - didier.villemin@ensicaen.fr \\ * Corresponding author \\ Keywords: \\ adsorption; magnetic nanoparticles; organic pollutants; phosphonated \\ polyethylenimine
}

\author{
Beilstein J. Nanotechnol. 2016, 7, 1447-1453. \\ doi:10.3762/bjnano.7.136 \\ Received: 15 March 2016 \\ Accepted: 21 September 2016 \\ Published: 13 October 2016
}

This article is part of the Thematic Series "Nanostructures for sensors, electronics, energy and environment III".

Guest Editor: N. Motta

(c) 2016 Monteil et al.; licensee Beilstein-Institut. License and terms: see end of document.

\begin{abstract}
Wastewater cleaning strategies based on the adsorption of materials are being increasingly considered, but the wide variety of organic pollutants at low concentrations still makes their removal a challenge. The hybrid material proposed here consists of a zwitterionic polyethylenimine polymer coating a magnetic core. Polyethylenimine is phosphonated at different percentages by a one-step process and used to coat maghemite nanoparticles. It selectively extracts high amounts of cationic and anionic contaminants over a wide range of $\mathrm{pH}$ values, depending on the adjustable number of phosphonate groups introduced on the polymer. After recovering the nanoparticles with a magnet, pollutants are quantitatively released by repeated washing with low amounts of $\mathrm{pH}$-adjusted water. The material can be reused many times without noticeable loss of efficiency and is designed to resist high temperatures, oxidation and harsh conditions.
\end{abstract}

\section{Introduction}

During the last decades, an increased emphasis was placed on the issue of diffuse contamination of water. Toxic metals and organic pollutants are significant sources of hazard for human health, even at low concentrations [1-3]. Many technologies such as photodegradation, biodegradation, the Fenton process, or extraction by liquid membranes have been developed to eliminate these compounds in wastewater [4-6]. Among them, adsorption-based methods are extensively studied $[7,8]$.
At the same time, the emergence of nanotechnologies has led to a new generation of organic/inorganic nanocomposites with embedded magnetic nanoparticles (NPs) [9-13]. The application of a simple magnetic field is sufficient to collect them, which fosters the development of low-cost recyclable processes. However, while many systems can efficiently remove hazardous metallic ions from waters, the elimination of organic micropollutants is still an issue $[11,14]$. Most of the materials are exclu- 
sively efficient for cationic or anionic molecules, and only few of them have been successfully tested on both [15]. In addition, they often adsorb a limited amount of contaminant, considerably lower than the capacity of activated charcoal.

We report herein a new adsorption process for water remediation, based on partially phosphonated polyethylenimine (PEIP)coated magnetic nanoparticles (NP-PEIP). The special feature of the PEIP is the presence of numerous ammonium and, more original, phosphonate groups spread on the polymer. Its zwitterionic structure allows the adsorption of any kind of charged contaminant. Unlike many others sorbents, this nanomaterial strongly resists the degradation caused by hydrolysis or oxidation, due to strong covalent $\mathrm{Fe}-\mathrm{O}-\mathrm{P}$ bonds [16]. As a result it can be indifferently used in acidic or basic media, in contrast to other sorbents based on silica shells or coatings with oligosaccharides [17].

\section{Experimental \\ Material and apparatus}

Polyethylenimine (25000 Da) was purchased from BASF, phosphorous acid, formaldehyde, hydrochloric acid and sodium hydroxide were obtained from VWR and dyes (methylene blue, MB, and methyl orange, MO) from Sigma-Aldrich. Dialysis tubings were bought from Roth. Absorbance was measured by using a UV-visible Perkin-Elmer Analyst 100 spectrophotometer. The microwave used was a Prolabo Synthewave. A Varian SpectrAA 55 AAS was used to detect potential traces of iron in the supernatants after collecting nanoparticles. Zeta potential measurements were determined by DLS analysis using a Malvern Zetasizer nanoZS model.

\section{Preparation of the phosphonated polyethylenimine-maghemite material Synthesis of nanoparticles}

Maghemite ionic ferrofluid ( $[\mathrm{Fe}]=10^{-2} \mathrm{~mol} / \mathrm{L}$ ) was prepared by wet alkaline coprecipitation according to the Massart protocol $[18,19]$. Iron(III) chloride and iron(II) chloride were co-precipitated at a molar ratio of 1:2, in the presence of ammonium hydroxide solution (28\%), at room temperature and under mechanical stirring. Then, a solution of iron(III) nitrate in concentrated nitric acid was added at $80^{\circ} \mathrm{C}$ under stirring. After the removal of the supernatant, nanoparticles were washed with acetone and diethylether and then redispersed in a controlled volume of water. The $\mathrm{pH}$ value of the ionic ferrofluid was about 2, with $\mathrm{NO}_{3}{ }^{-}$as counterion. Nanoparticles are spherical, with an average diameter of $7 \mathrm{~nm}$ determined by XRD [17].

\section{Synthesis of the polyethylenimine phosphonate}

Phosphonated polyethylenimine (PEIP) was prepared as previously described $[20,21]$. An adjustment of the amounts of phos- phorous acid and formaldehyde is necessary to obtain phosphonated polyethylenimine with different percentages of phosphonation $(\mathrm{P} \%)$. We have prepared a large range of phosphonated polyethylenimine with a percentage varying from 5 to $90 \%$ [20]. For the calculations, we have considered that a molecule of PEI is constituted of monomers $\left(\mathrm{CH}_{2}-\mathrm{CH}_{2}-\mathrm{NH}\right)_{n}$ with an average molecular mass of 43 . So, for example, to synthesize PEIP with $\mathrm{P} \%=20,3.81 \mathrm{~g}\left(0.2\right.$ equiv, $\left.4.65 \cdot 10^{-2} \mathrm{~mol}\right)$ of phosphorous acid $\mathrm{H}_{3} \mathrm{PO}_{3}$ were introduced in $10 \mathrm{~g}$ of PEI (25000 Da, $4 \cdot 10^{-4} \mathrm{~mol}$ of PEI corresponding to $23.2 \cdot 10^{-2} \mathrm{~mol}$ of monomer $\mathrm{CH}_{2} \mathrm{CH}_{2} \mathrm{NH}$ ) in $30 \mathrm{~mL}$ of water, and the mixture was irradiated $(150 \mathrm{~W})$ for $1 \mathrm{~min}$ in a microwave oven. $10 \mathrm{~mL}$ of concentrated $\mathrm{HCl}$ and $9.30 \cdot 10^{-2} \mathrm{~mol}$ of a $35 \%$ formaldehyde solution were successively added. After 5 min of irradiation, excess of formaldehyde was removed under vacuum and the solution was dialyzed with a nitrocellulose membrane, yielding $85 \%$ of PEIP [22].

\section{Preparation of NP-PEIPx powder}

An amount of $5 \mathrm{~mL}$ of diluted ferrofluid in water $\left([\mathrm{Fe}]=10^{-4} \mathrm{~mol} \cdot \mathrm{L}^{-1}\right)$ were added dropwise to $10 \mathrm{~mL}$ of a PEIP solution $(30 \mathrm{mg} / \mathrm{mL})$ adjusted to $\mathrm{pH} 2$ with diluted nitric acid under vigorous stirring. After $15 \mathrm{~min}$, sodium hydroxide was added to destabilize the solution. The supernatant was removed and the precipitate redispersed in $10 \mathrm{~mL}$ of $1 \mathrm{~mol} \cdot \mathrm{L}^{-1}$ nitric acid by sonication. Then acetone was added until NP-PEIP precipitated. These were washed successively with acetone and diethylether and then dried in an oven at $120{ }^{\circ} \mathrm{C}$ for $24 \mathrm{~h}$.

\section{Preparation of stock solutions}

MO or MB powders were dissolved in distilled water $\left(5 \cdot 10^{-4} \mathrm{~mol} \cdot \mathrm{L}^{-1}\right)$ in order to prepare dye stock solutions.

\section{Extraction of methyl orange and methylene blue with NP-PEIP}

A particles stock solution was prepared by dispersing $5 \mathrm{mg}$ of NP-PEIP powder in $50 \mathrm{~mL}$ of distilled water. All the following experiments ( $\mathrm{pH}$ value, kinetic, maximum of adsorption...) were repeated five times.

\section{pH Adsorption studies}

The experiments were carried out for both NP-PEIP20 and NP-PEIP80. A range of samples was prepared by introducing $10 \mathrm{~mL}$ of NP-PEIP stock solution in $10 \mathrm{~mL}$ of the dye solution. For all of them, the $\mathrm{pH}$ was adjusted between 1 and 14 with either diluted nitric acid or sodium hydroxide solution. After $3 \mathrm{~h}$ of stirring, particles were collected with a magnet, and the supernatant was removed. The particles were rinsed twice with $1 \mathrm{~mL}$ of distilled water, which was afterwards added to the liquid phase. Supernatant absorbance was monitored by UV-visible spectrophotometry. It is noteworthy that OM exhib- 
its acido-basic properties and is used as $\mathrm{pH}$ indicator. At $\mathrm{pH} 14$, the OM absorption wavelength does not vary $(\lambda=465 \mathrm{~nm})$, neither does the molar extinction coefficient $\varepsilon$ (Figure S3 in Supporting Information File 1). So, in the case of the MO solution, the supernatants were adjusted to $\mathrm{pH} 14$ by addition of sodium hydroxide before recording the absorption in order to avoid a distortion of the measurements (Figure S4 in Supporting Information File 1). For MB, this problem does not occur and we have established calibration curves according to the $\mathrm{pH}$ values (Figure S5 and Figure S6 in Supporting Information File 1).

\section{Kinetic studies}

The experiments were carried out for both NP-PEIP20 and NP-PEIP80. 15 replicate tests were prepared for each dye, using the same protocol as previously, but with a constant $\mathrm{pH}$ value (7 for $\mathrm{MO}, 14$ for $\mathrm{MB}$ corresponding to the $\mathrm{pH}$ value of maximum adsorption). Evolution of absorbance was monitored by spectrophotometry and recorded at different times, changing the sample between measurements.

\section{Washing step}

Acidic and basic wash waters were obtained by adjusting distilled water to $\mathrm{pH} 2$ or 14 with diluted nitric acid $\left(1 \mathrm{~mol} \cdot \mathrm{L}^{-1}\right)$ and a solution of sodium hydroxide respectively $\left(0.1 \mathrm{~mol} \cdot \mathrm{L}^{-1}\right)$. $10 \mathrm{~mL}$ of NP-PEIP stock solution were mixed with contaminant solutions as described above, at the $\mathrm{pH}$ value of maximum adsorption (MO: $\mathrm{pH} 7$, MB: $\mathrm{pH} 14$ ) for $3 \mathrm{~h}$. After that, the particles were re-dispersed in $20 \mathrm{~mL}$ of wash water per milligram of NP-PEIP depending on the pollutant: MO was washed with the acidic solution, MB with the basic one. After 5 min of stirring, the particles were collected with a magnet and the supernatant absorbance of each run was monitored by spectrophotometry.

\section{Recyclability}

Five replicate tests were conducted to guarantee the reproducibility of the results. $20 \mathrm{mg}$ of NP-PEIP $(\mathrm{P} \%=20)$ were dispersed in $20 \mathrm{~mL}$ of the dye stock solution and vigorously stirred for $4 \mathrm{~h}$. Then, the particles were collected with a magnet and the absorbance of the supernatant was monitored by spectrophotometry. Four washing steps were carried out between each cycle, and the particles were directly reused in the new dye solution batch.

\section{Results and Discussion \\ Magnetic material preparation and conditions of the studies}

The novelty of this contribution consists in the use of PEI with phosphonic groups allowing a solid grafting of PEI on the maghemite nanoparticles, by the formation of strong covalent $\mathrm{P}-\mathrm{O}-\mathrm{Fe}$ bonds. The presence of these negative phosphonic groups ensures the stability of NP regardless of the $\mathrm{pH}$ value, especially in very basic medium, which is not the case for plain PEI [23].

The phosphonated groups are introduced on PEI through the modification of primary and secondary amines according to the Moedritzer and Irani synthesis [24]. In a previous work we described the synthesis, the coating of maghemite and a characterization of the physicochemical properties of the material [20,22]. As illustrated in Figure 1, PEIP can be customized to contain more or less phosphonated groups, by varying the percentage of amines modified (P\%). Between pH 3 and 10, the zeta potential is positive but decreases with the percentage of phosphonation (see Figure S2 in Supporting Information File 1). After the point of zero charge (PZC), the phosphonates induce a negative charge, whereas non-phosphonated PEI-NP display a zeta potential of $0 \mathrm{mV}$, making PEI-NP unstable at basic $\mathrm{pH}$.

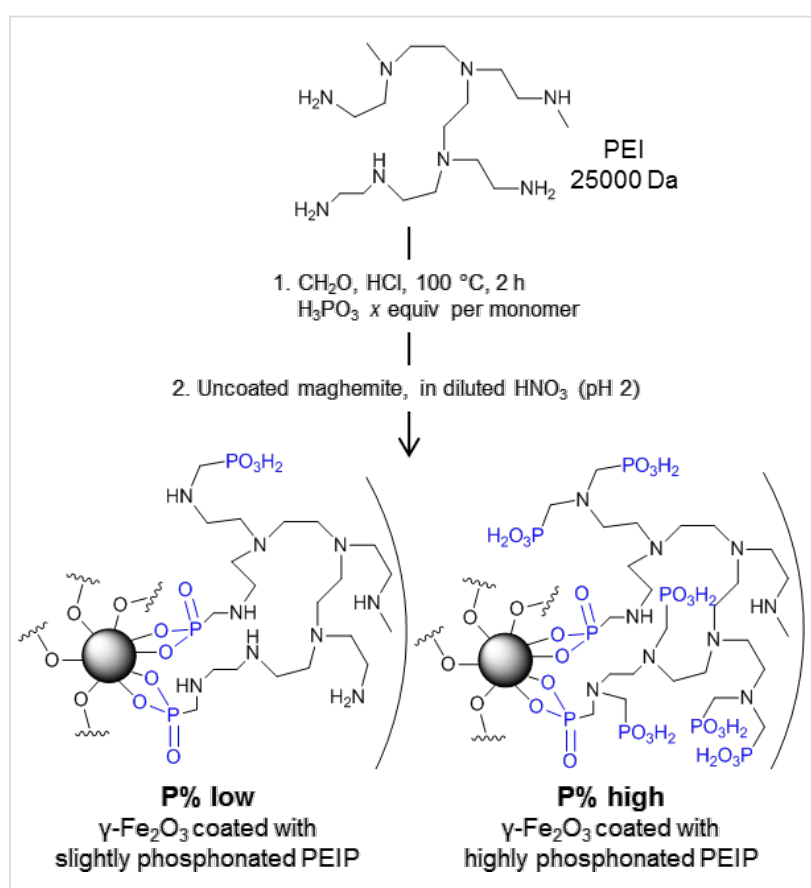

Figure 1: Synthesis of NP-PEIP. The number of phosphonates depends on the number of equivalents of phosphorous acid used.

The efficiency of the NP-PEIP in removing pollutants was determined by the adsorption of two organic dyes used as contaminants models: the positively charged (regardless of the $\mathrm{pH}$ value) methylene blue (MB) and the negatively charged (from $\mathrm{pH} 3.4$ to basic $\mathrm{pH}$ ) methyl orange (MO). Such dyes are pollutants themselves. They are widely used for industrial purposes, especially MB in the textile industry [25], they reduce light penetration and photosynthesis in the effluents. Their removal remains a challenge [26]. 
With the aim of evaluating the interactions of the NP-PEIP material with pollutants in very low quantities, which are considerably harder to remove, the concentration of the dyes was kept below $5 \cdot 10^{-4} \mathrm{~mol} \cdot \mathrm{L}^{-1}$ in all the experiments. This choice of low concentration (which is not a strict limitation) is dictated by the need to be close to the most common pollutions that are often diffuse and characterized by low concentration levels. Moreover, the MO and MB calibration curves have been evaluated (data available in Figures S3-S6 in Supporting Information File 1) and show that their absorptions vary significantly either with the $\mathrm{pH}$ or with the concentration. It can be observed that working at low concentrations allows one to avoid the di- or trimerization of $\mathrm{MB}$, which dramatically impacts the wavelength of the maximum absorption.

\section{Determination of the optimal conditions}

First, we studied the $\mathrm{pH}$ value at which a maximum of dye is loaded on the particles. Adsorptions in solutions of MO or MB were carried out at different $\mathrm{pH}$ values using two types of particles as sorbents: one coated with a slightly phosphonated polymer $(\mathrm{P} \%=20, \mathrm{NP}-\mathrm{PEIP} 20)$ and another coated with a highly phosphonated polymer $(\mathrm{P} \%=80$, NP-PEIP80).

Figure $2 \mathrm{~A}$ shows that the maximum of the anionic dye MO is recovered between $\mathrm{pH} 4$ and 10 . The percentage of phosphonation does not significantly affect the $\mathrm{pH}$ range of efficiency, only the amount of MO adsorbed: $870 \mathrm{mg} / \mathrm{g}$ for NP-PEIP20, whereas $350 \mathrm{mg} / \mathrm{g}$ only for NP-PEIP80. On the other hand, the adsorption of the cationic dye MB by NP-PEIP20 is constantly low $(\leq 40 \mathrm{mg} / \mathrm{g})$ below $\mathrm{pH} 10$. We assume that the positive charges on the ammonium groups cause electrostatic repulsions with the cationic dye. In the case of NP-PEIP80, the PEI carried many phosphonate groups and the resulting numerous negative charges decrease the repulsion between ammonium and MB. Consequently, up to $700 \mathrm{mg} / \mathrm{g}$ of MB can be extracted by NP-PEIP80. The MB adsorption increases up to $1000 \mathrm{mg} / \mathrm{g}$ above $\mathrm{pH} 10$.

The kinetic curves, presented Figure 2B, highlight the fast MO extraction regardless of the $\mathrm{P} \%$ value. Indeed, $50 \%$ of maximum adsorption capacity is reached after only $4 \mathrm{~min}$ and $21 \mathrm{~min}$ in the two cases. MB is removed more slowly: 37 and 60 min for $\mathrm{P} \%=80$ and $\mathrm{P} \%=20$ respectively, are needed to load half of the pollutants on the NP-PEIP. That confirms the assertion that the adsorption rate is strongly dependent on the amount of phosphonate groups on the polymer. First measurements were monitored only after five minutes: This time was necessary to ensure the collection of all the NP-PEIP with the magnet. It can be explained by the dispersion state of the particles in solution, and the nanometric size. The sensitivity to the magnetic attraction is lower for nanometre-sized beads than for

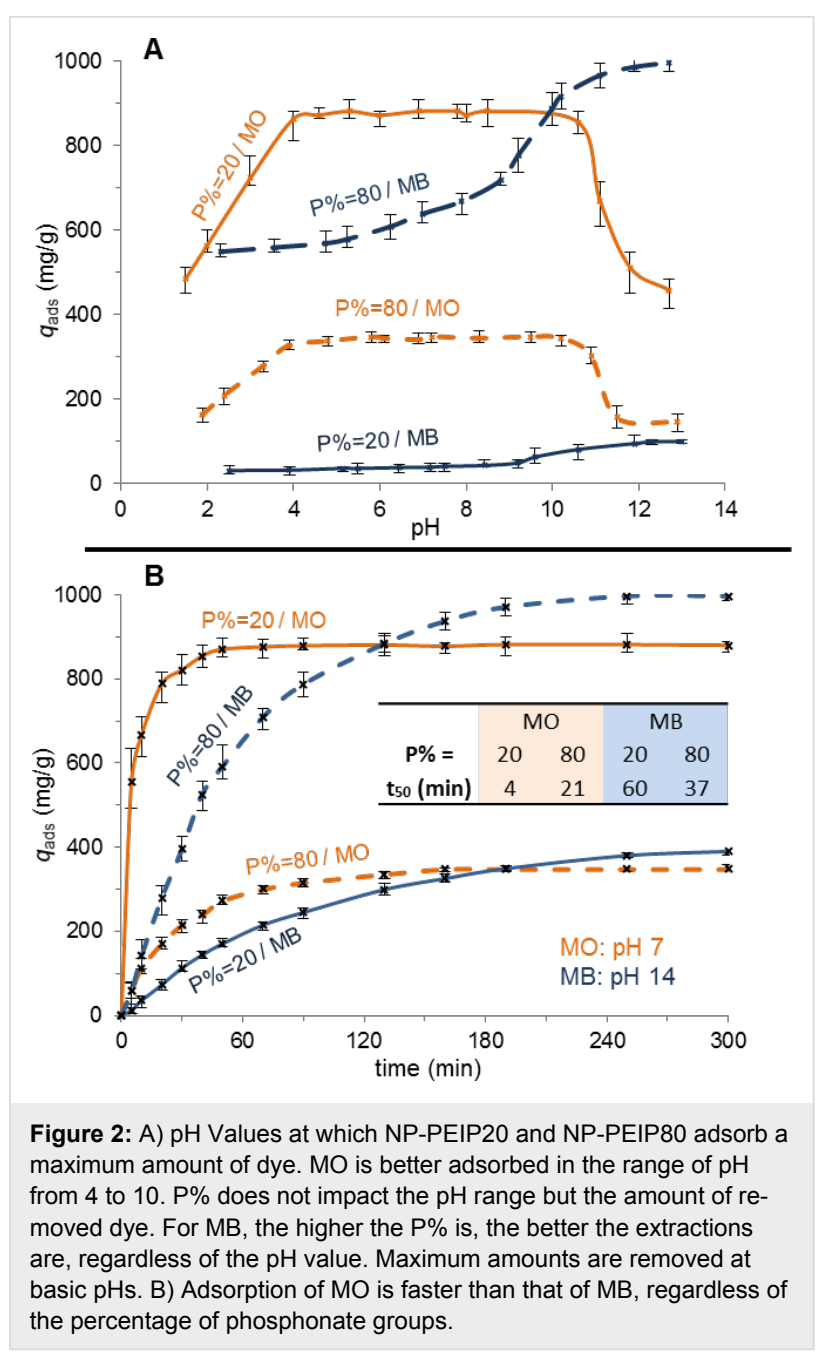

micro- or millimetre-sized beads in which many maghemite nanoparticles are often incorporated in a polymeric network.

\section{Interpretation of the $\mathrm{pH}$-responsive pollutant extraction}

To understand these results, a diagram predicting the specific interactions between particles and dyes according to the $\mathrm{pH}$ value is showed in Figure 3. Phosphonate functions on the NP-PEIP are in the monodeprotonated $\mathrm{RPO}_{3} \mathrm{H}^{-}$form above $\mathrm{pH} 2$, and undergo a second deprotonation $\left(\mathrm{RPO}_{3}{ }^{2-}\right)$ around $\mathrm{pH}$ 6.5-7.0. In the presence of both ammonium and phosphonate groups, only ammonium interactions are represented because they are always in the majority, therefore they have strongest influence on the behaviour of the particles.

We can predict that the MO extraction is maximized between $\mathrm{pH} 3.4$ (above its $\mathrm{p} K_{\mathrm{a}}$ ) and $\mathrm{pH} 10.5$, corresponding to the amine deprotonation on the NP-PEIP. In this range of $\mathrm{pH}$, the electrostatic interactions between numerous ammonium and MO sulfonate groups are at the maximum intensity. Concerning the MB, 


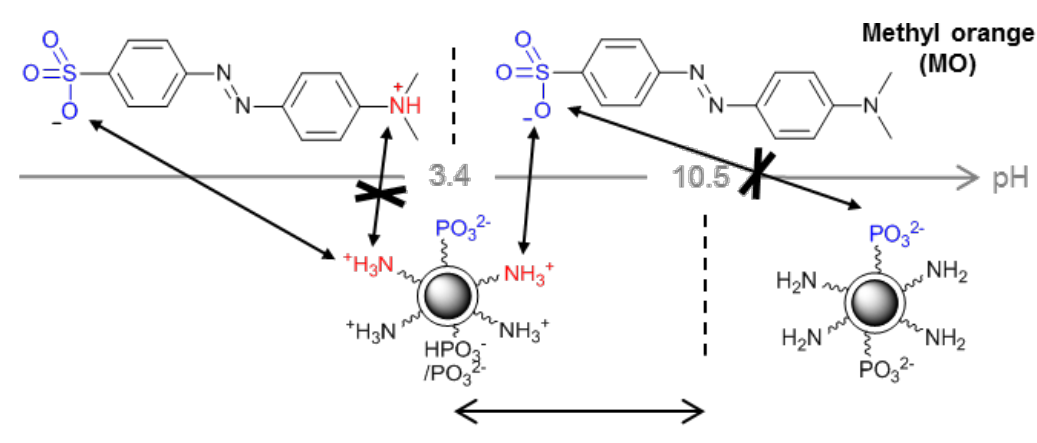

Theoretical $\mathrm{pH}$ of maximum adsorption

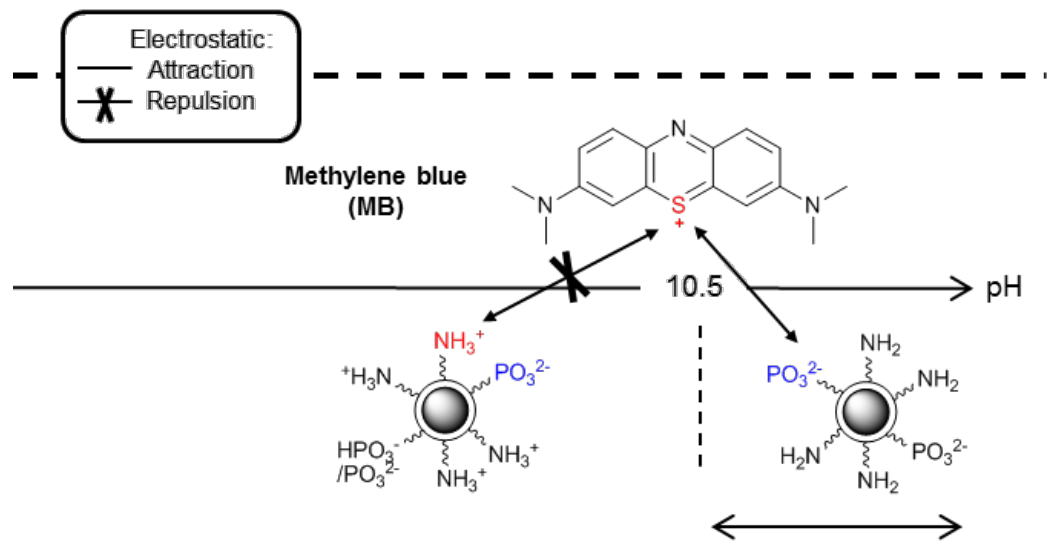

Theoretical $\mathrm{pH}$ of maximum adsorption

Figure 3: Prediction of the best range of $\mathrm{pH}$ values for electrostatic attractions between NP-PEIP and MO and MB dyes. Only the major interaction (i.e., ammonium) is represented. For $\mathrm{MO}$, an interaction occurs with sulphates and ammonium groups, until the $\mathrm{pK}$ $\mathrm{MB}$ is attracted by the phosphonate groups introduced on $\mathrm{PEI}$ at basic $\mathrm{pH}$ values.

the sulfur atom is always positively charged. The adsorption therefore increases after the second deprotonation of phosphonate, and is maximized above $\mathrm{p} K_{\mathrm{a}}$ of the ammonium/amine deprotonation, where repulsive forces are negligible. All of these results show that, in the case of maghemite coated with phosphonated PEI adsorbing MO and MB, electrostatic interactions are predominant.

\section{Quantities of pollutant extracted according to the percentage of phosphonation}

Performances of remediation for nanoparticles coated with different polymers $(\mathrm{P} \%=5,20,60,90)$ are summarized Figure 4. The maximum efficiency is reached at $\mathrm{pH} 7$ for $\mathrm{P} \%=5$, where the system can remove up to $1356 \mathrm{mg} \cdot \mathrm{g}^{-1}$ of MO. When $\mathrm{P} \%$ increases, the amount of adsorbed dyes, $q_{\max }$, drop: $882 \mathrm{mg} \cdot \mathrm{g}^{-1}$, $510 \mathrm{mg} \cdot \mathrm{g}^{-1}$ and up to $314 \mathrm{mg} \cdot \mathrm{g}^{-1}$ for NP-PEIP20, NP-PEIP60 and NP-PEIP90, respectively. Referring back to Figure 3, the repulsion between negative charges increases with the number of introduced phosphonate groups. At pH 14, we observe a similar evolution, but all values of $q_{\max }$ are much lower because of the absence of electrostatic attraction, whereas all the amino groups are deprotonated.

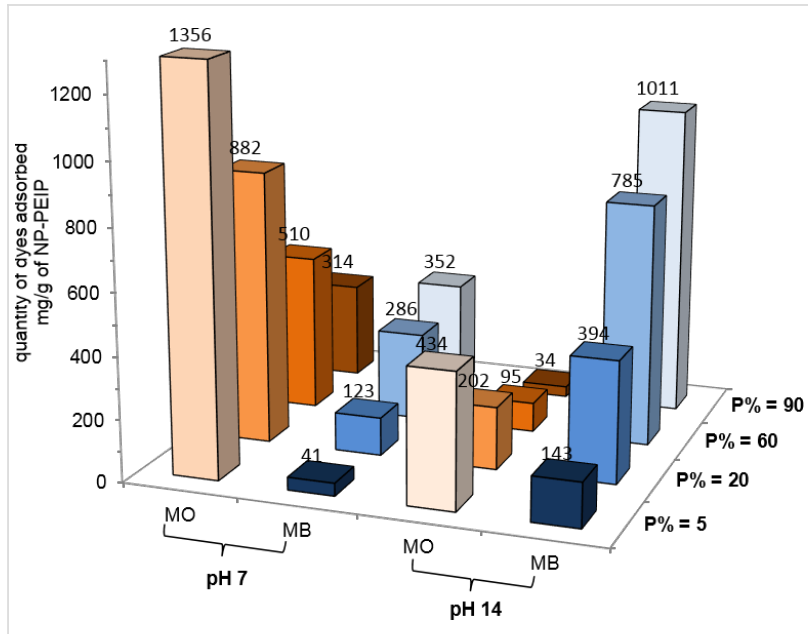

Figure 4: Removed amounts of $\mathrm{MO}$ and $\mathrm{MB}$ dyes by NP-PEIPx at $\mathrm{pH}$ 7 and 14 . P\% significantly affects adsorption of MB and MO. At neutral $\mathrm{pH}$, much more $\mathrm{MO}$ is eliminated than $\mathrm{MB}$, while the contrary is observed at basic $\mathrm{pH}$.

The phosphonation rate also strongly influences the adsorption of MB. The value of $q_{\max }$ is increased to the seven-fold between $\mathrm{P} \%=5$ and $\mathrm{P} \%=90$ at $\mathrm{pH} 14$ with a maximum of 
$1011 \mathrm{mg} \cdot \mathrm{g}^{-1}$. This amount is higher than the commercial activated charcoal $\left(980 \mathrm{mg} \cdot \mathrm{g}^{-1}\right)$ and among the largest measured extracted amounts of BM dye [27]. This high $q_{\max }$ can be attributed to the composition of NP-PEIP: PEIP represents more than $80 \%$ of the particles total weight [20], and under the same conditions maghemite does not adsorb more than $1 \mathrm{mg} / \mathrm{mg}$. In addition, each monomeric unit of the PEIP potentially interacts with charged pollutants through amine or phosphonate groups.

\section{Washing steps and recyclability of the mag- netic particles}

The data collected in Figure 4 reveal that the adsorption of MO with NP-PEIP05 is reduced to one third between pH 7 and 14 . On the opposite, the MB adsorption falls from $1011 \mathrm{mg} \cdot \mathrm{g}^{-1}$ to $352 \mathrm{mg} \cdot \mathrm{g}^{-1}$ with NP-PEIP90 when the $\mathrm{pH}$ value decreases from 14 to 7 . Consequently, the washing process is easy to implement, by successive redispersions of collected particles in basic or acidic water, for anionic MO and cationic MB pollutants, respectively. The washing solutions consist of water adjusted to pH 7 or 14 with nitric acid or sodium hydroxide. Moreover, only $20 \mathrm{~mL}$ are enough to wash up to $1 \mathrm{~g}$ of magnetic particles. Figure 5A shows that after a full adsorption of MO by NP-PEIP05 (orange bars), more than $68 \%$ of dye are released after the first wash and $83 \%$ after two successive washes. NP-PEIP90 loaded with MB (blue bars) release $76 \%$ and $88 \%$ after the first and the second wash, respectively. Consequently, we can reasonably estimate that four washes are enough to obtain a reusable material practically purified.

NP-PEIP05 and NP-PEIP90 were also evaluated in several adsorption/desorption cycles (Figure 5B). A little loss of activity for MO and MB was observed but more than $90 \%$ of contaminants were removed after the seventh cycle. The loss in magnetic particles between cycles is negligible compared to the amount of pollutant extracted and in addition, no traces of iron were detected by atomic absorption spectroscopy in the supernatant. The decreasing of effectiveness is already under study.

\section{Conclusion}

The modulation of positive and negative charges of phosphonated polyethylenimine, through the controlled insertion of phosphonate groups on polyethylenimine, can be considered as an advantage for adsorption of organic pollutants. By adjusting the percentage of phosphonation, the $\mathrm{pH}$ value and the decontamination time, performances similar to active charcoal are obtained, but with a highly selective adsorption of cationic and anionic contaminants. This recyclable material obtained by an easy and reproducible single-step process is particularly designed for water treatment. Moreover, the PEIP polymer is perfectly adaptable for a future use in other systems such as microbeads or membranes.
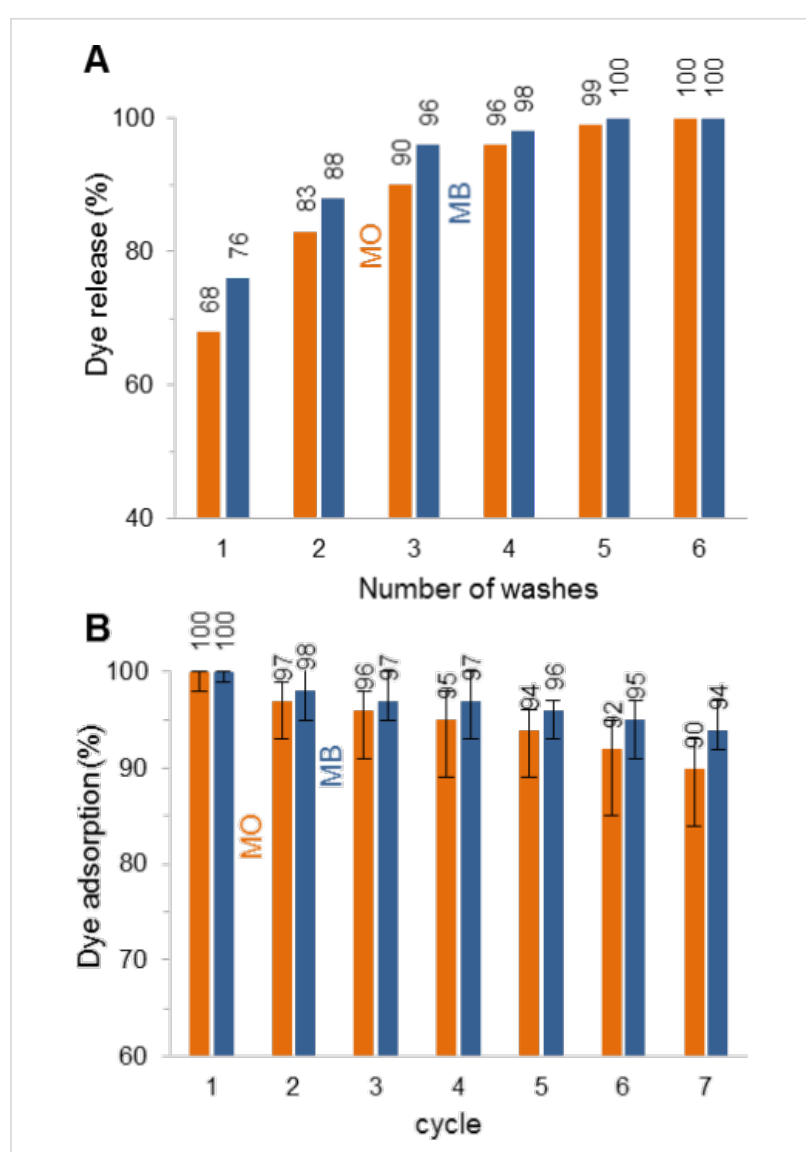

Figure 5: A) Cumulative quantities of dyes released after each wash. $\mathrm{MO}$ is desorbed from NP-PEIP05 with sodium hydroxide aqueous solution, MB from NP-PEIP90 with diluted nitric acid. B) The efficiency of the dyes extraction remains high after several adsorption/desorption cycles.

\section{Supporting Information}

Supporting information includes a TEM image of the synthetized maghemite nanoparticles, evolution of the zeta potential of maghemite, PEI nanoparticles and PEIP-coated nanoparticles as a function of the $\mathrm{pH}$ value, and evolution of the maximum absorption wavelengths and molar extinction coefficients of methyl orange and methylene blue, and corresponding calibration curves.

\section{Supporting Information File 1}

Additional experimental data.

[http://www.beilstein-journals.org/bjnano/content/ supplementary/2190-4286-7-136-S1.pdf]

\section{Acknowledgements}

We gratefully acknowledge financial support from the 'Ministère de la Recherche et des Nouvelles Technologies', CNRS (Centre National de la Recherche Scientifique), the 
'Région Basse-Normandie' and the European Union (FEDER funding). The authors acknowledge the financial support of the french Agence Nationale de la Recherche (ANR), through the program "Investissements d'Avenir"(ANR-10-LABX-09-01), LabEx $\mathrm{EMC}^{3}$.

\section{References}

1. Cotruvo, J. A. Sci. Total Environ. 1985, 47, 7-26. doi:10.1016/0048-9697(85)90316-X

2. Richardson, S. D.; Ternes, T. A. Anal. Chem. 2011, 83, 4614-4648. doi:10.1021/ac200915r

3. Schwarzenbach, R. P.; Escher, B. I.; Fenner, K.; Hofstetter, T. B.; Johnson, C. A.; von Gunten, U.; Wehrli, B. Science 2006, 313, 1072-1077. doi:10.1126/science.1127291

4. Martínez-Huitle, C. A.; Brillas, E. Appl. Catal., B: Environ. 2009, 87, 105-145. doi:10.1016/j.apcatb.2008.09.017

5. Rivas, B. L.; Pereira, E. D.; Palencia, M.; Sánchez, J. Prog. Polym. Sci. 2011, 36, 294-322. doi:10.1016/j.progpolymsci.2010.11.001

6. Crini, G. Bioresour. Technol. 2006, 97, 1061-1085. doi:10.1016/j.biortech.2005.05.001

7. Liu, P.; Zhang, L. Sep. Purif. Technol. 2007, 58, 32-39. doi:10.1016/j.seppur.2007.07.007

8. Dias, J. M.; Alvim-Ferraz, M. C. M.; Almeida, M. F.; Rivera-Utrilla, J.; Sánchez-Polo, M. J. Environ. Manage. 2007, 85, 833-846. doi:10.1016/j.jenvman.2007.07.031

9. Khin, M. M.; Nair, A. S.; Babu, V. J.; Murugan, R.; Ramakrishna, S. Energy Environ. Sci. 2012, 5, 8075-8109. doi:10.1039/c2ee21818f

10. Zhong, L.-S.; Hu, J.-S.; Liang, H.-P.; Cao, A.-M.; Song, W.-G.; Wan, L.-J. Adv. Mater. 2006, 18, 2426-2431. doi:10.1002/adma.200600504

11. Koehler, F. M.; Rossier, M.; Waelle, M.; Athanassiou, E. K.; Limbach, L. K.; Grass, R. N.; Günther, D.; Stark, W. J. Chem. Commun. 2009, 4862-4864. doi:10.1039/b909447d

12. Obeid, L.; Bée, A.; Talbot, D.; Ben Jaafar, S.; Dupuis, V.; Abramson, S.; Cabuil, V.; Welschbillig, M. J. Colloid Interface Sci. 2013, 410, 52-58. doi:10.1016/j.jcis.2013.07.057

13. Xu, P.; Zeng, G. M.; Huang, D. L.; Feng, C. L.; Hu, S.; Zhao, M. H.; Lai, C.; Wei, Z.; Huang, C.; Xie, G. X.; Liu, Z. F. Sci. Total Environ. 2012, 424, 1-10. doi:10.1016/j.scitotenv.2012.02.023

14. Wang, H.; Chen, Q.-W.; Chen, J.; Yu, B.-X.; Hu, X.-Y. Nanoscale 2011, 3, 4600-4603. doi:10.1039/c1nr11012h

15. Luo, X.; Zhang, L. J. Hazard. Mater. 2009, 171, 340-347. doi:10.1016/j.jhazmat.2009.06.009

16. Mutin, P. H.; Guerrero, G.; Vioux, A. J. Mater. Chem. 2005, 15, 3761-3768. doi:10.1039/b505422b

17. Zhao, H.; Xu, J.; Lan, W.; Wang, T.; Luo, G. Chem. Eng. J. 2013, 229, 82-89. doi:10.1016/j.cej.2013.05.093

18. Massart, R. IEEE Trans. Magn. 1981, 17, 1247-1248. doi:10.1109/TMAG.1981.1061188

19. Lefebure, S.; Dubois, E.; Cabuil, V.; Neveu, S.; Massart, R. J. Mater. Res. 1998, 13, 2975-2981. doi:10.1557/JMR.1998.0407

20. Monteil, C.; Bar, N.; Moreau, B.; Retoux, R.; Bee, A.; Talbot, D.; Villemin, D. Part. Part. Syst. Charact. 2014, 31, 219-227. doi:10.1002/ppsc.201300185

21. Villemin, D.; Moreau, B.; Elbilali, A.; Didi, M.-A.; Kaid, M.; Jaffrès, P.-A. Phosphorus, Sulfur Silicon Relat. Elem. 2010, 185, 2511-2519. doi:10.1080/10426501003724897
22. Monteil, C.; Bar, N.; Retoux, R.; Henry, J.; Bernay, B.; Villemin, D. Sens. Actuators, B 2014, 192, 269-274. doi:10.1016/j.snb.2013.09.096 23. Xu, Y.; Qin, Y.; Palchoudhury, S.; Bao, Y. Langmuir 2011, 27, 8990-8997. doi:10.1021/la201652h

24. Moedritzer, K.; Irani, R. R. J. Org. Chem. 1966, 31, 1603-1607. doi:10.1021/jo01343a067

25. Bennani Karim, A.; Mounir, B.; Hachkar, M.; Bakasse, M.; Yaacoubi, A. Rev. Sci. Eau 2010, 23, 375-388. doi:10.7202/045099ar

26. Ali, H. Water, Air, Soil Pollut. 2010, 213, 251-273. doi:10.1007/s11270-010-0382-4

27. Rafatullah, M.; Sulaiman, O.; Hashim, R.; Ahmad, A. J. Hazard. Mater. 2010, 177, 70-80. doi:10.1016/j.jhazmat.2009.12.047

\section{License and Terms}

This is an Open Access article under the terms of the Creative Commons Attribution License

(http://creativecommons.org/licenses/by/4.0), which permits unrestricted use, distribution, and reproduction in any medium, provided the original work is properly cited.

The license is subject to the Beilstein Journal of

Nanotechnology terms and conditions:

(http://www.beilstein-journals.org/bjnano)

The definitive version of this article is the electronic one which can be found at: doi:10.3762/bjnano.7.136 